\title{
THE SAS STRATEGY TRAINING FOR CHILDREN WITH ASD IN INCLUSIVE EDUCATIONAL ROBOTICS ACTIVITIES
}

\author{
Andromachi Nanou ${ }^{1}$, Evaggelia Tsiomi ${ }^{2}$, Andreas Oikonomou ${ }^{3}$, \\ Dimitris Karampatzakis ${ }^{4}$ \\ 1,2,4 Department of Computer Science, International Hellenic University, Greece \\ ${ }^{3}$ Department of Education, School of Pedagogical and Technological Education, Greece \\ ${ }^{1,2}$ Interdisciplinary Network for Special and Intercultural Education, Greece
}

\begin{abstract}
Educational Robotics in inclusive learning environments creates a wide area of research where innovative teaching practices and theoretical approaches are developed and investigated in order for the new growing educational challenges to be met. In this context, an educational intervention research was carried out using mixed research methodology. The aim of the research was to investigate the effect of the "SAS Strategy Training" a strategy that developed to foster the participation of children with autism, at level 2, in inclusive teamwork with peers during construction and programming LEGO Mindstorms. 2 children, 10-11 years old, diagnosed with autism, at level 2, participated in two inclusive educational robotics teams with typical peers. The SaS Strategy has been integrated in the collaboration script that was designed to support the interaction between the team members during their collaboration on programming LEGO Mindstorms. The "SaS Strategy Training" had encouraging results in reducing the barriers of the participation of the children with autism in teamwork with their typical peers. Critical questions, reflections and new research horizons emerged.

Keywords: Inclusion, Participation, Educational Robotics, Lego Mindstorms, collaboration scripts, autism.
\end{abstract}

To cite this article:

Nanou, A., Tsiomi, E., Oikonomou, A., \& Karampatzakis, D. (2021). The SAS Strategy Training for Children with ASD in Inclusive Educational Robotics Activities. Education. Innovation. Diversity, 2(3), 34-52. DOI: https://doi.org/10.17770/eid2021.2.6723

\section{Introduction}

Educational Robotics (ER) is an innovative and promising discipline with a focus on how robots can foster or support human learning processes in formal or informal learning environments (Barker \& Ansorge, 2007). ER studies interests in those kinds of robots that children can manipulate and interact with for educational purposes. The Educational Robots receive instructions designed and executed through algorithms by the children themselves, to control the behaviour of the robot and complete a specific task (Pivetti et al., 2020). Although the literature reveals a lot of difficulties that are being raised for the effective integration of ER in curriculum, this trend in education have been already introduced into the classroom, from kindergarten through high school, as the design, assembly and programming of ER require the use of principles from different sciences such as engineering, computers, mathematics, and physics.

ER supports the learning processes in different ages and enhance of various skills such as logical reasoning, critical thinking, and creativity (Blanchard, Freiman, \& Lirrete-Pitre, 2010; Miller, Nourbakhsh, \& Siegwart, 2008), problem solving, social interaction and teamwork (Benitti, 2012). Recently, new research outcomes demonstrated that ER bridges gaps that lead to risks of social marginalization and subsequent risks of early school leaving by improving learning motivation, interest in learning itself and engagement of children with disabilities in active learning processes (Daniela \& Lytras, 2019).

The last ten years, much work has been conducted to investigate the effectiveness of ER engagement of children with disabilities (Pivetti et al., 2020; Sannenan et al., 2020; Tsiomi \& Nanou, 2020; Hinchliffe, Saggers, Chalmers \& Hobbs, 2016; Yuen, Mason \& Gomez, 2014; 
Wainer et al., 2010;). The interest of many of the authors focused on which kind of robots, which educational methods and specific collaborative or cooperative strategies promote the engagement of children with ASD or with other kinds of disabilities and foster the learning possess the emotional, cognitive, or social skills. Most of the research work had been conducted in special educational settings.

Although ER is being applied in inclusive learning environments, very little research has been conducted in this field (Hinchliffe, Saggers, Chalmers, \& Hobbs, 2016; Tsiomi \& Nanou, 2020). As the learning environment all over the world becomes more inclusive, there is a need to develop successful inclusive practices and theories within the inclusive context in all fields in formal and non-formal education (Seale et al 2014; Nanou et al., 2020; Nilholm, 2021).

The aim of the present study is to investigate the effectiveness of an educational intervention focused on teaching children with Autism Spectrum Disorder (ASD) at Level 2, a specific strategy, under the name Search and Share Strategy (SaSS), to foster their participation in teamwork with peers during inclusive ER constructive and programming activities with LEGO Mindstorms. The proposed strategy was devised to solve the problem of how children with ASD could be fostered to participate in teamwork during ER activities. This problem emerged after our previous research work in the field of inclusive ER where children with ASD were included (Tsiomi \& Nanou, 2020). SaSS Training that was based on the structured teaching (Mesibov \& Howley, 2003) extends Legoff's method of assigning specific roles to children with ASD in teamwork during LEGO constructing play. The SaSS Training had been applied in two teams of three 10-11 years old children where two children with autism were included. The participation of children with ASD had been assessed by participant and independent observers, through observation protocols and research diaries. A rubric used for the description of the SaSS usage by children with autism. Data analysis followed a mixed research methodology.

\section{Literature Review}

In inclusive environments, it is important for all students to participate and to learn according to their needs. Children with ASD included in formal or non-formal educational environments have the same desire in using ER technologies and to participate, as their typical peers, in the educational process. Participation is the key to childhood development and the "best predictor" of learning for children with autism (Iovannone, Dunlap, Huber, \& Kincaid, 2003). According to the psychosocial approach, the Participation has two dimensions: Attendance and Involvement. Attendance is related to the objective dimension of the concept and takes on the meaning of "I'm here". The Involvement, however, has emotional components such as motivation, involvement, perseverance, and sociability in the sense of interaction and interconnection and. On a personal level the content of Involvement means engagement (Immset al., 2017). According to researchers' statement "Sustainable learning can occur only when there is meaningful engagement. The process of engagement is a journey which connects a child and their environment (including people, ideas, materials and concepts) to enable learning and achievement"(Carpenter, Carpenter, Egerton, \& Cockbill, 2016). Engagement "In the person level is the internal state of individuals involving focus or effort: (page 20) (Imms et al., 2017).The engagement of children in ER designing, assembling, programming, testing, debugging, and modification activities presupposes effective collaboration and teamwork. Participants in an ER activity are invited to collaborate on the design and construction of a robot that is required to carry out a project. Collaboration requires students to be active and involved (Yuen et al., 2014; Tsiomi \& Nanou, 2020).

However, children with ASD face barriers in communication and socialization that negatively affect their social interactions and participation in activities of day life. People with 
ASD are less engaged in social or physical activities compared to their typically developing peers (Askari et al. 2015, Simpson, Imms, \& Keen, 2021). Research and clinical data have shown that teamwork between typical and non-typical students does not usually lead to substantial learning outcomes if specific rules are not agreed between the team members (Bell, 2004; Hewitt, 2005; Liu \& Tsai, 2008). The effective engagement of children with ASD in an ER learning environment depends on the degree of the structuring of the learning environment (Mesibov \& Howley, 2003). Structure is oriented by specific collaboration scripts and rules being defined to support teamwork. It is strongly recommended, except in the ER environment, that the interactions between students must be structured (Dillenbourg, 2002).

According to the research findings, when the teamwork in inclusive ER learning environments is structured using specific collaborative or cooperative strategies, the participation of the children with ASD is increased. More specifically, it was documented by previous research in inclusive ER settings, that specific cooperative strategy for structuring the activities and the processes of sharing ideas had positive results in fostering the participation of children with ASD and social interactions of typical and non-typical peers (Tsiomi \& Nanou, 2020; Tsiomi, Pashalidou \& Nanou, 2020). Additionally, one of the best outcomes concerning the participation of children with ASD in teamwork during LEGO construction play have been documented after the assigning of specific roles to each child with ASD in the team (Legoff, 2004). Legoff, in order to promote teamwork during LEGO construction play, structured the teamwork process, assigning different responsibilities between children with ASD (e.g., a child is given a set of instructions and acts as "engineer"; another child has the necessary pieces to make the set and acts as the "supplier"; and another child is the "builder", who is assigned the task putting the pieces together, following the instructions of the engineer). Positive results concerning the participation and social interaction of children with ASD peers have been documented (Legoff, 2004; Pang, 2010).

In inclusive ER learning environments, where children with ASD are included, specific strategies have to be developed in order for the learning environment, the learning processes and the collaboration to be structured. During ER activities with peers the collaboration process (e.g. verbal interaction, active gesturing, physical contact) is important to be structured if our intent is children with ASD to gain social interaction and skills (Yuen et al., 2014). Teamwork strategies are strongly recommended to be presented by visual stimuli in order for the participation of children with ASD to be effective (Tsiomi \& Nanou, 2020; Albo-Canals et al., 2015). Specific strategies that could impose a specific structure on how children with ASD could interact with peers during teamwork inclusive educational robotic activities need to be developed especially for children with ASD in Level 2 that need substantial support for effective collaboration (American Psychiatric Association, DSM 5, 2013).

\section{The aim of this study}

This study aims at investigating the effects of SaSS Training in the participation of children with Level 2 ASD as "suppliers", in teamwork with typical peers during the inclusive ER activities with LEGO bricks and ER LEGO Mindstorms.

\section{Research questions}

More specifically, with our intervention we try to give answers to the following questions:

1. Will the SaSS training reduce the barriers and increase the successful participation of children with ASD in Level 2 in the teamwork with peers a) during the construction activities with LEGO blocks? b) During the design of the LEGO Mindstorms robot? and c) during programming activities of LEGO Mindstorms robot?

2. Will the children with ASD learn to use the SaSS autonomously in teamwork with their peers? 


\section{Methodology}

\section{Research Methodology}

Educational intervention is chosen as the most suitable research method. Educational intervention is a qualitative study that involves the design, implementation and evaluation of a proposal or curriculum in a particular course and can be related to either the content or the teaching process. Requires measurements before and after the intervention. Comparing the results of the measurements before and after the educational intervention, the researchers test the success or failure of the educational intervention (Damaskinidis \& Christodoulou, 2019).

Educational intervention gives answers to educators, questions like: «what works, in what context, with which groups, and at what cost» (Hutchinson. 1999). It is also based on detailed and well-timed planning, in a way that accurately records all the steps of the educational process; measurements are provided before and after the intervention so that an improvement can be calculated (Hutchinson, 1999).

Place, schedule, and educational equipment

The educational intervention took place at the "Tokei Maru - School for all", located in Triandria Thessaloniki, Greece. It lasted at 12 Meetings of ER activities (M1-M12) once a week, and for a period of three months. Each Meeting had a duration of 90 minutes. The schedule (day and time) of each Meeting was fixed. The ER equipment consisted of two kits of NXT LEGO Mindstorms kits were used, one for each team. The children followed an assembling process through the LEGO Mindstorms manual using two 10 inch tablets. The practice in robotics was done on a track $(2,40 \mathrm{~m} \times 1,20 \mathrm{~m})$ intelligently designed for ER activities with LEGO Mindstorms.

\section{Participants}

6 children separated in two teams, team A of three boys and team B of three girls, 10-11 years old, were selected to participate in the activities of the inclusive ER educational programme. In each group a child with ASD was included.

All children participated with the permission of their parents in the after-school activities of "Tokei Maru - School for all". The children with ASD did not have any experience in LEGO Mindstorms constructing and programming activities. They were selected to join this activity because they had a keen interest in structured LEGO play. The children with typical development were selected because they were interested in joining robotic activities. They were experienced in ER and familiar in collaboration with ASD children at "Tokei Maru" before.

\section{Table 1 Teams of participants in relationship with researchers}

\begin{tabular}{|c|c|c|c|c|c|}
\hline & \multicolumn{3}{|c|}{ Participants } & \multicolumn{2}{c|}{ Researchers } \\
\hline & Name & Role in the team & Diagnosis & Observers & Coordinator \\
\hline \multirow{3}{*}{ A } & A.1 & Architect & typical & \multirow{2}{*}{2} & \\
\cline { 2 - 4 } & A.2 & Supplier & ASD & \\
& A.3 & Builder & typical & & \\
& B.1 & Architect & typical & \multirow{2}{*}{2} & \\
\cline { 2 - 4 } B & B. 2 & Supplier & ASD & & \\
\cline { 2 - 4 } & B.3 & Builder & typical & & \\
\hline
\end{tabular}

The children with ASD were both diagnosed by the Greek Public Educational and Counselling Support Center. According to their psychiatric evaluation their functionality was detected at Level 2. ASD people diagnosed with Level 2 have moderate symptoms, showing deficits in verbal and non-verbal social communication skills and limited ability to start social interaction. They need substantial support (American Psychiatric Association DSM 5, 2013). 
According to the diagnosis, the boy, named Christos, found it difficult to adapt to new social situations and environmental changes. Although he had extensive vocabulary, he rarely participated in dialogue. He responded effectively to instructions when presented to him visually. He responded with one word in the dialogue context. He was very skilled in constructive play with blocks. The girl, Lina, needed substantial support in social interaction. She used to speak with short sentences. Her expressive vocabulary was limited to everyday situations. She responded in the dialogue slowly and she used to discuss specific topics. Although she loved art and constructive play with LEGO, she kept her interest for a limited time, and she was working slowly.

\section{Educational Methodology}

In the context of educational intervention, the inclusive ER programme followed a specific collaboration script (Kollar, Fischer, \& Hesse, 2006). The collaboration scripts are scaffolds that shape the collaboration by structuring the interaction process in computer supported collaborative learning. Scaffolding supports learners to accomplish tasks that they are not able to accomplish on their own and it is derived by Vygotsky as a concept of the Zone of Proximal Development (Vygotsky, 1992; Wood et al., 1976).The collaboration script of this educational intervention followed five components:

I. the learning objective: The children with ASD learn to participate as "suppliers" in teamwork with peers during ER inclusive activities

II. the type of activities: Designing and programming the NXT LEGO Mindstorms into its basic movements, going forward and performing a square to reach specific LEGO objects in the track. The NXT LEGO Mindstorms were selected as an educational tool that functions as a magnet of interest, to enhance the participation and collaboration between children at each team. The NXT LEGO Mindstorms facilitate the construction play with structured blocks and computational bricks that allow users to create their own robots (Lauwaert, 2008). The assembly kit contains building block pieces and a programmable control unit that can enable one to build several robots. It allows users to assemble robots, program the movement, interface sensors and motors without focusing on technical details. The process of assembling and making the robot work involves basic understanding of physical and design principles and elementary programming skills (Afari \& Khine, 2017). NXT platform provides students with the opportunity to "test their programming skills" as what they are programming through the LEGO Mindstorms robot. They can visually understand "what works" and "what does not work" and "why". LEGO Mindstorms robots provide students with the opportunity to understand fundamental computer programming concepts that are, by their very nature, abstract (Afari \& Khine, 2017).

One of the greatest advantages of the LEGO Mindstorms for the participation of children with ASD is that the model structure for the assembling step by step is being represented in the detailed manual that is being included into the kit. These detailed visually structured manuals describe all the facilitated play options, step by step (Lauwaert, 2008). Through the detailed manuals the structured activities are visually organized and presented in a planned, sequential, and logical way. This kind of manual is effective in facilitating the constructing play of children with ASD (Hampshire \& Hourcade, 2014). Although structured block play with LEGO is suitable for individual play of children with ASD in collaborative robotic projects specific strategies must be developed and taught in order everyone in the team has its role and to keep the collaboration process. Collaborative robotics projects require students to work together to solve a robotic task. For example, students can work together to design and build a robot that will find an object, pick it up, and 
move it to another location (Yuen et al., 2014. Children with ASD face difficulties in initiating or responding to social interactions and need the support of specific strategies to collaborate with peers (Silva et al., 2020).

The implementation phases of SaSS during the 12 Meetings (M1-M12) are the following:

- Phase A: Construction activities with LEGO blocks (M1-M3),

- Phase B: Robot design (M4-M5), and

- Phase C: Programming (M6-M12).

The ER program activities in each meeting is presented below:

- M1: Assessment meeting on LEGO construction without the intervention or the support of special educators.

- M2-M3: LEGO construction using LEGO Educational material.

- M4-M5: Robot design: Construction of the NXT LEGO Mindstorms using the SaSS with optical verbal or physical guidance.

- M6-M8: Programming $1^{\text {st }}$ mission, Moving front and going back. Each team works on a tablet. Children with ASD are being asked to transfer the blocks to the tablet following the standard image on colour printed cards, using the SaSS with optical, verbal or physical guidance.

- M9-M11: Programming $2^{\text {nd }}$ mission, Go forward, come back and turn four times like a square.Children with ASD are being asked to transfer the blocks to the tablet following the standard image on colour printed cards, using the SaSS with optical, verbal or physical guidance.

- M12:Assessment meeting on Programming $1^{\text {st }}$ and $2^{\text {nd }}$ missions without intervention or the support of special educators.

III. the sequence component: The sequence in the script specifies the activities learners should perform and when they should perform them (Kollar, Fischer, \& Hesse, 2006).In order for the sequence component to be followed the Search and Share Strategy (SaSS) steps were designed to structure the ER activities in this educational intervention. The SaSS was devised based on the experience gained by our action research that is conducted for many years with children on the autism spectrum (Tsiomi \& Nanou, 2020) as well as study of the relevant literature and especially the Legoff method (Legoff, 2004). The SaSS determines the specific steps that a child with ASD must follow to participate as a productive "supplier" while working with the "architecture" and the "builder" in the ER team. The children have to share bricks during LEGO construction or robot design and share information during programming of the robot Lego Mindstorms.
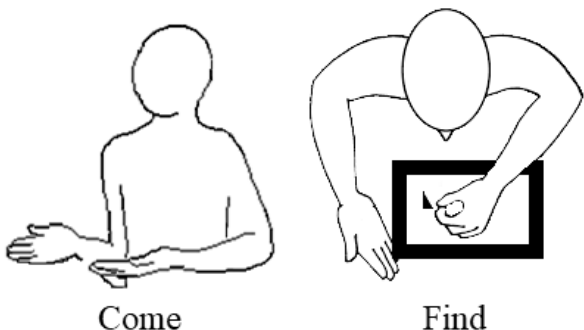

Find

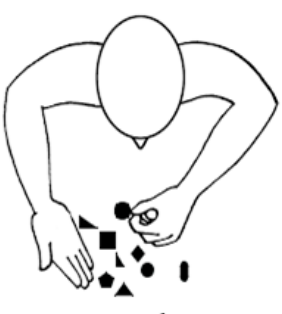

Look

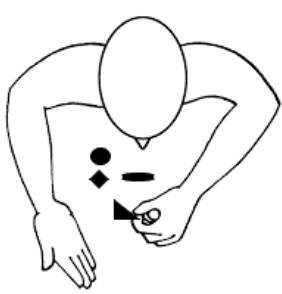

Look for

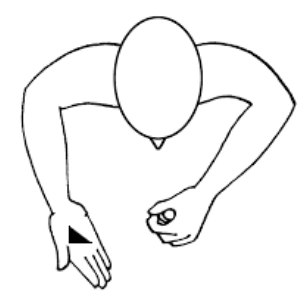

Give

Figure1 The five steps of the SaS Strategy

The SaSS consists of five steps, as illustrated in Figure 1.The steps are presented visually to prepare more precisely the children with ASD to use the SaSS during the A,B and C phase of the programme. The steps are:

(1) Come - the child is invited by the teacher to come to the training area, 
(2) Look - the child is verbally encouraged by the teacher to focus on the desired point of construction,

(3) Look For - the child is encouraged by the teacher to seek to find the necessary piece either with physical or verbal guidance,

(4) Find - the child finds and confirms with the requested piece,

(5) Give - the child gives the piece and focuses on the assembly process.

IV. the role distribution component: Specific roles addressed to the participants during the teamwork in ER activities. These roles had specified according to Legoff's work on construction play with LEGO (Legoff, 2004) (see Table 1)

$V$. the representation component: This component refers to the type of representation of the components of the script. In our educational intervention emphasis had been given to the representation of the SaSS which constitutes the sequence component of the script. As the SaSS training addressed to the children with ASD the visual representation had been chosen (see Figure 1).

\section{Data Collection}

Data concerning the participation of the children with ASD after the SaSS training during the Phases (A, B, C) were collected through observation methods and tools. Observation consists of the main method of data collection in ER activities (Bernstein, Mutch-Jones, Cassidy, \& Hamner, 2020).

Two observers, special pedagogues, observed the ASD children's participation in the two teams (4 observers in total). The Independent Observer (IO) was to observe the participation processes of the children with ASD in each team without taking part in the robotic activities. The Participant Observers (PO) was the one that supported the children with ASD in each group to efficiently use the SaSS. Participatory observation combines participation in activities under study by maintaining a professional distance that allows appropriate observation and data recording.

Both the observers used structured and unstructured observation methods and tools for data collection. Work diary was used as an unstructured observation method. Work diaries were used by both the participant and independent observer of each team just after the end of each meeting in order their observations and interpretations were recorded. In addition, they recorded methodological notes about her role in the context, her relations with the other researchers, participants, her personal impressions and feelings or practical issues arising in the field (Feldman, Altrichter, Posch, \&Somekh, 2018; Willig, 2008). At the end of each activity, a feedback discussion is held between the observers and special educators to evaluate the educational process.

\section{Rubric for the assessment of autonomy in the use of SaSS by children with ASD}

A unique rubric has been designed for the specific research as a tool for the assessment of the level of autonomy in the implementation of the SaSS by the children with ASD in teamwork during the constructive and programming robotic activities. Rubrics are effective and efficient tools that are being used for the objective evaluation of a range of performances or activities in any subject area (Stevens \& Levi, 2005). The level of autonomy in the usage of every step of the SaSS was being accessed by both the coordinator and the independent observer at each group at the beginning of the constructing or programming process in all meetings (M1M12).

The rubric that has been designed for the purpose of the research aims at evaluating the degree of autonomy in participation of the children with ASD in each of the five SaSS steps: 1) Come, 2) Look, 3) Look for, 4) Find, and 5) Give. The coordinator of both teams and the independent observer of each team had to assess the participation in each process using a scale 
of grades 0-5 that represent the levels of autonomy in the implementation of the strategy. More specifically (0) declares the absence of participation, (1) the intention of participation, (2) the participation with Physical guidance of a special educator, (3) the participation after verbal reminders, (4) the participation with visual reminders, and (5) the autonomous participation. The designing of the rubric followed the scaffolding processes derived by Vygotskyan concept of the Zone of Proximal Development (Vygotsky, 1992).

How data was classified and analysed

For data analysis mixed methods were used. According to Creswell and Clark (2007), "Data analysis in mixed methods consists of analysing the qualitative data using quantitative methods" (p.128).

Categorical productive approach was chosen for Qualitative data analysis (Isaris \& Purkos, 2015). The reason that the productive rather than the inductive approach in categorical analysis was chosen dictated by the aim of the research, which was to find out specific reactions, that could be given information concerning the participation of children with ASD as suppliers in the inclusive educational robotics program and how this participation achieved. The research data recorded by the observers in their diaries were analysed in content units that focus on participation and have been categorized according to two thematic categories: Observation of the Barriers in participation. These specific thematic categories were predefined to focus and highlight data that are related to the issues being investigated by the research questions (Isaris $\&$ Purkos, 2015). In order for the $1^{\text {st }}$ and $2^{\text {nd }}$ research questions to be answered the Barriers and Successes in participation of children with ASD as they were recorded in the research diaries were counted.

\section{Research Findings}

\section{1st Research question}

Will the SaSS Training reduce the barriers and increase the successful participation of children with ASD in Level 2 in the teamwork with peers a) during the construction activities with LEGO blocks? b) during the design of the LEGO Mindstorms robot? c) during the programming activities of LEGO Mindstorms robot?

The data concerning the $1^{\text {st }}$ research question came up by the categorical analysis of the observations included into the research diaries of both the Participant Observer (PO) and the Independent Observer (IO) during the A, B and C Phase.

After the categorical analysis, 110 content units were identified through the research diaries of both the Participant (60 units) and the Independent Observer (50 units) concerning the participation of the boy with ASD in teamwork with peers during the three phases $(\mathrm{A}, \mathrm{B}$ and C) of the SaSS Training. 17 content units into the Independent Observer's diaries have been categorized as Barriers and 43 as Successes of participation. 14 content units into the Participant Observer's diaries categorized as Barriers and 36 as Successes in participation of the boy with ASD.

The agreement between the two observers (IO and PO) was checked with the Cohen's Kappa index. Specifically, regarding the the boy's participation Barriers, the index for the weaknesses of cooperation took a value of 0.660 which ranks the agreement between the observers in a significant agreement (above average) at the level of importance $p=0.001$ and for the successes with a value of 0.4 which classifies it as a moderate agreement between the observers with a significance level $\mathrm{p}=0.002$.

Figure 2 presents the average of the observed Barriers and Successes of the boy during the 12 Meetings. 


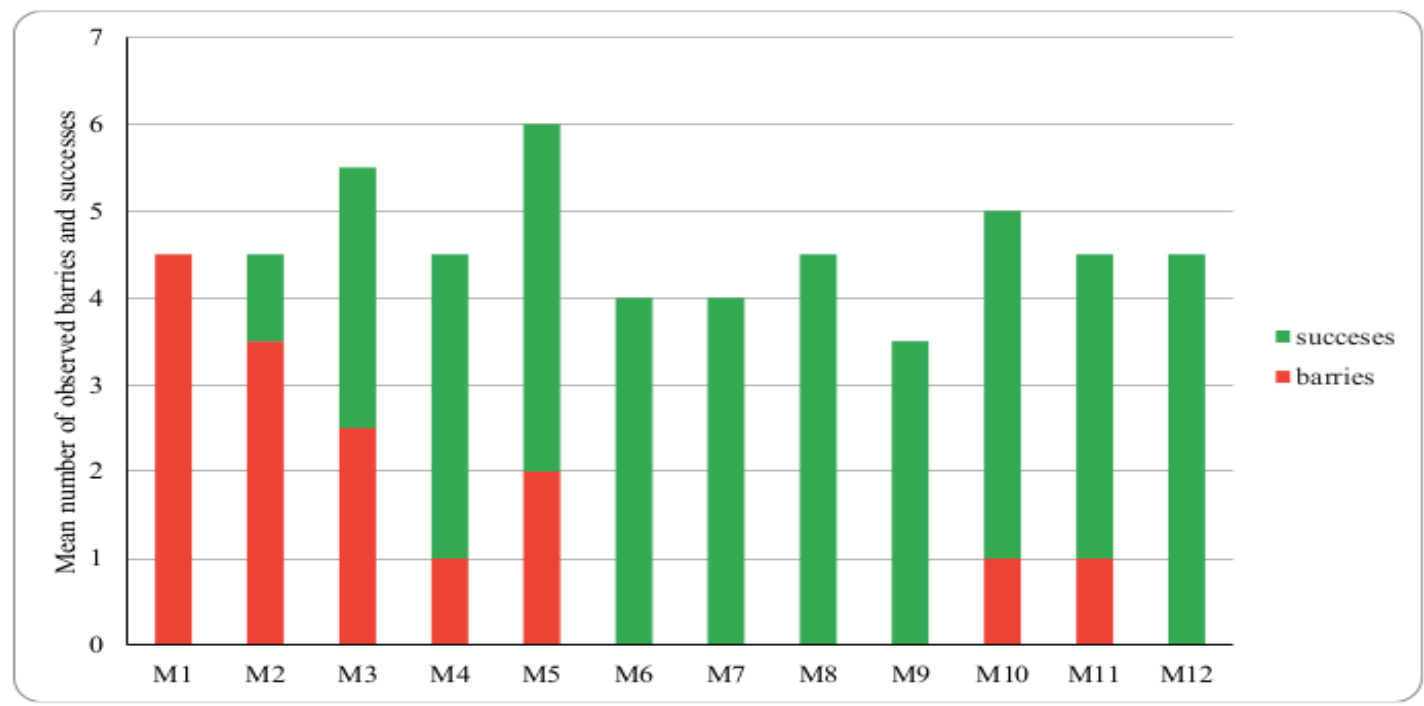

Figure 2 The average of the observed barriers and successes of the boy's participation in each session until the completion of the 12 meetings of the boys' group

Concerning the participation of the girl with ASD in teamwork with peers, 126 content units were identified through the research diaries of both the Participant (62 units) and the Independent Observer (64 units) during the three phases (A, B and C) of the SaSS Training. The Independent Observer recorded 28 barriers and 34 successes while the Participant Observer recorded 34 barriers and 30 successes.

The agreement between the two observers (IO and PO) was tested with Cohen Kappa index, showed for each category of semantic coherence above average relevance at the significance level $p=0.001$. Regarding the Barriers, the Cohen Kappa index for the weaknesses of cooperation took a value 0.571 , which ranks the agreement of the observers at the upper levels of mediocrity at the level of significance $\mathrm{p}=0.001$ and regarding the Successes of participation, took a value 0.564 , which also ranks the agreement between observers at the upper level of the median, in terms of significance, $p=0.001$.

Figure 3 presents the average of the observed Barriers and Successes of the girl's participation during the 12 Meetings.

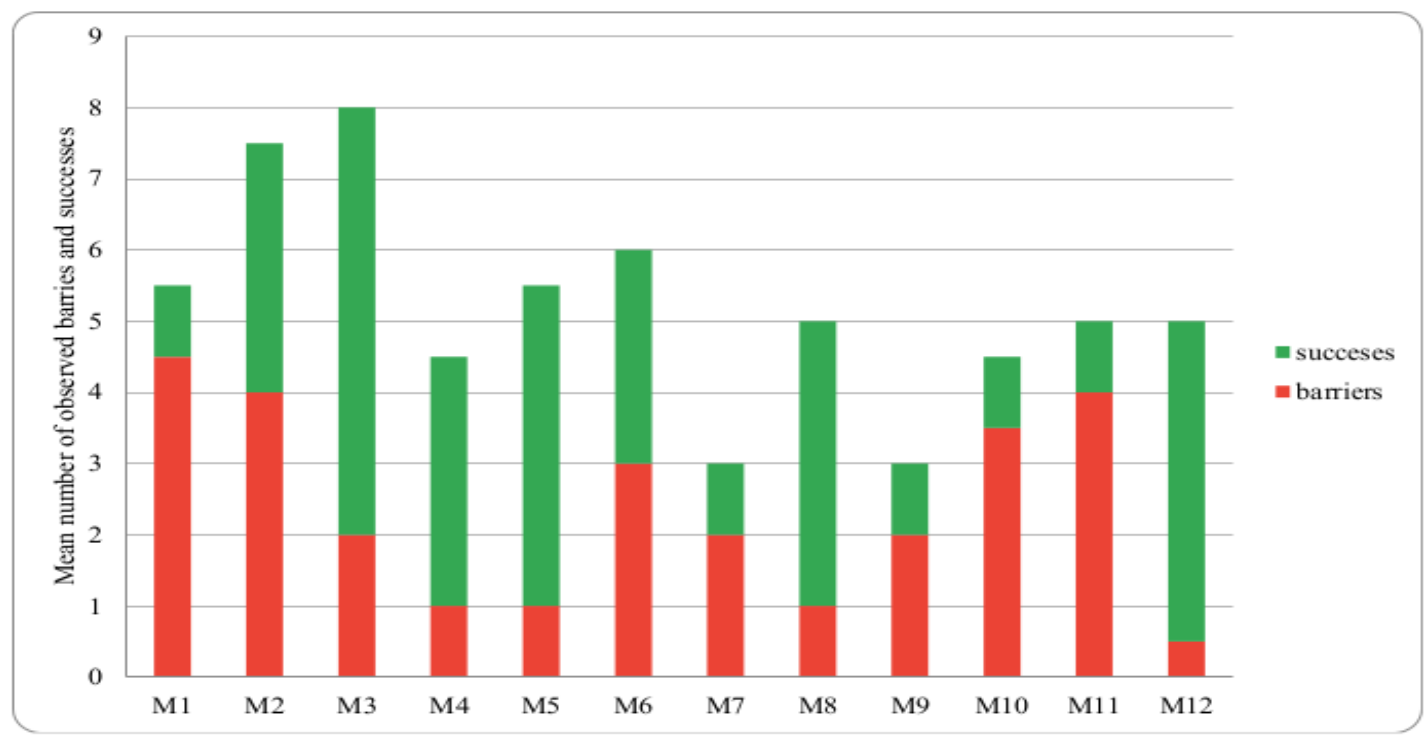

Figure 3 The average of the Barriers and Successes recorded by the observers of girl's participation during the Meetings (M1-M12) 
Differences in the participation between the boy, Christos and the girl, Lina, were determined, with the girl facing more Barriers, especially in the programming Phase $(\mathrm{C})$. More specifically, during the Phase (A) in constructing play with LEGO, both the girl and the boy were facing Barriers at the same degree. In the second phase (B) during robot design the Barriers were decreased. But in Phase (C) during the programming, Barriers for the boy were reduced, while for the girl was increased.

The Barriers and the Successes of participation of both children with ASD, Christos and Lina, while using SaSS in teamwork are described in detail with the comments of the observers as they were recorded into their dairies. The data from the observations of A and B Phases are presented concerning the boy first and the girl next.

During M1 more Barriers than Successes were recorded in the boy's participation. Christos entered the Tokei Maru with his personal LEGO toys and played alone only with them throughout the Meeting. He chose not to participate in the teamwork with peers. While he was talking to himself he was looking at the team working. Although the boys asked him to participate he preferred to stay alone. During M2, boys asked Christos to join their team from the beginning of the Meeting. Although he approached the team, he didn' stop playing with his own LEGO constructions. He was helped by the special pedagogue to come close to the team, but he had a parallel construction play. The independent observer noted in her diary;

"Christos looked like not want to participate. The boys had understood that he was really good at construction so they tried to find some ways to interact with him"

When the boys asked him to present his LEGO constructions he responded:

"These are my constructions. They are vehicles"

During M3, robot design Phase (B), Christos, under the guidance of the special pedagogue, put his personal LEGO toys in a box and left them visible. Special pedagogue helped and ensured that he could have visual contact with his toys any time during the Meeting. The team of boys sat at the table and the special pedagogue presented visually the SaSS describing the steps one by one. The independent observer noted:

"The boys helped to put on the table the pictures of the SaSS steps and the starting letters of each step that on the pictures because Christos could recognize the alphabet letters"

They started assembling the robot in which Christos participated following the SaSS steps with the help of the special pedagogue and with the support of the other boys. The SaSS pictures were sent to his parents by email so that Christos could study the pictures and be better prepared. During M4, Christos' participation progressively increased with longer duration. Christos had learned the routine of entering the room, putting his personal toys in the transparent box and sitting at the table with his team members where the SaSS pictures were put. At first, he started to follow the steps with physical guidance by the special pedagogue. The participant observer wrote in her diary:

"The Mindstorms manual and the construction of the collaboration process through the SaSS strategy, helped him to organize his participation during the robot design and to contribute as a member of the team"

In the M5 it is noted that he was upset when he entered the room. Although he was confused, he participated in the construction of the robot. He helped his team to find the correct pieces with the guidance of the special pedagogue.

Concerning the participation of the girl with ASD, Lina, during M1, more Barriers than Successes were recorded. From the first time Lina joined the girls, the members of her team talked with them asking their names. Thus, while responding to the call of her team members to focus her gaze and attention on the book of orders for LEGO construction, she participated only in the role of the observer without proceeding with the search and finding of the appropriate block. 
During M2 and M3 after she was taught the steps of SaSS by pictures with the support of the special pedagogue her participation became more successful. The Participatory Observer, special pedagogue, noted the Barriers that Lina was face:

"She looked at the brick shown to her in the guide, raised her hand to look for the pieces but reassembled her hand as if unsure. she needed physical guidance to complete the steps"

The SASS pictures were, also, sent to her parents, so that Lina could study them before the next Meeting. At M4 and M5 Lina was involved in the process of assembling the robot. According to both the Independent and the Participant Observers, Lina participated successfully during the robot design (Phase B). The reason was due to the robot components that were settled in the specific places in the kit. This arrangement of the components in the kit made it easier for Lina to search and locate the blocks the team was looking for. Throughout the process the support of the special educator was necessary, especially when Lina lost her concentration. During the Phases A and B of the SaSS Training there was progressive closeness and success in involving children in assembly teamwork.

Findings from the Phase $\mathrm{C}$ are presented below for both the boy and the girl:

During M6, Christos' participation improved. Although the means of implementation were changed and a tablet with the programming software was added through the NXT platform, the participation of the child continued, and in fact because he had a special interest for digital media, his participation was of better quality. He was significantly helped by the SASS pictures that were put during the Meeting on the table. During the Step Give of SaSS Christos had to put in the "programming frame" the programming blocks using the touch screen of the tablet. The team decided how many blocks Christos had to put in the "programming frame" and he became the "supplier" of the blocks during programming.

During M7, Christos' participation continued to be active. He managed to put all the blocks even though they were increased. In the M8, Christos made his routine at the entrance, placing his toys in the box. This time he approached his group alone after the children's call. He follows the steps of the SaSS with minimal guidance from the special pedagogue. He successfully transferred the blocks and when he completed his mission, he gave the tablet to the next one. In M9 they programmed robots to move on. Christos followed the steps of the SaSS and transferred the appropriate blocks. However, because these were more, they needed verbal guidance from the special educator. He was enthusiastic about the robot's movement. The children completed the arrangements for the robot's movement and Christos watched the team in programming tests. During M10-M11 he entered with great enthusiasm. He followed his routine and approached the team alone. He followed the steps of the SaSS and the cooperation was constructive. The support of the special pedagogue was deemed necessary in the steps that Christos seemed to have difficulty in (numbering the necessary blocks for programming). In the last meeting Christos followed the verbal guidance of the special pedagogue to stay in his team and work together placing the blocks. The special pedagogue's notes in her diary "Christos could be taught how to adjust the other parameters in order to control the movement of the robot".

On the other hand, during M6-M7, a decrease in Lina's successes was observed according to both the Observers. This change was attributed to the activities of programming during the Phase C. During this phase the teamwork was differentiated. As a result, it was difficult for Lina to participate especially during the 7th Meeting. According to the observers, Lina's behaviour was affected negatively by the constant movements of the girls of her team, who were moving all the time while programming and testing their robot on the track. These new conditions in their collaboration were unexpectedly differentiated according to the previous M2-M5 collaboration conditions, in which less movement was required. Even when the special pedagogue showed Lina the steps of the programming process visualized, she found that Lina had a difficulty in concentrating. The special pedagogue, as she realized that difficulty, asked 
the girls of her team to stay at the table, next to Lina, in order to complete the programming in a specific place. In the following meetings (M8-M9) the planning process was visually structured to facilitate Lina's participation. Except for the SaSS pictures, pictures of the exact number of blocks that Lina had to transfer to the canvas-programming surface were placed on the table. The construction positively affected Lina's participation, which seems to have increased according to the observers of cooperation possibilities. Lina started following the team on the track and participating by giving the command with the support of her team girls in the robot to move. Although her participation was mechanistically she understood the process and her role in the team, as "supplier".

Lina found it difficult to participate in the programming process during the next Meetings. The independent observer notes:

"The programming process was complex as it required eight blocks that Lina had to measure and place on the canvas in a row".

The comparison of the Successes and Barriers of participation of both boys and girls between the 1st and the 12th Meeting when there was no support by special pedagogues is presented in Figure 4.

The Barriers in participation for both the boy and the girl were reduced from M1 to M12. Although the boy, during M1 had no Success in his participation as he worked alone, at the final Meeting M12, his participation was totally successful, according to both observers. Christos was accepted as a member of the ER team and participated in the process of construction and programming of Lego Mindstorms, using the SaSS. On the other hand, the girl, Lina, although from the first meeting she had positive interaction with the girls' team, needed strong support from the special pedagogue to participate effectively in the programming Phase. At the last Meeting M12 faced Barriers using the SaSS but she managed to collaborate with the guidance of the other girls of her team. Of course, as one observer points out, it was obvious that her participation was achieved without the corresponding understanding of concepts and programming algorithms, concepts that the other members of the team understood.
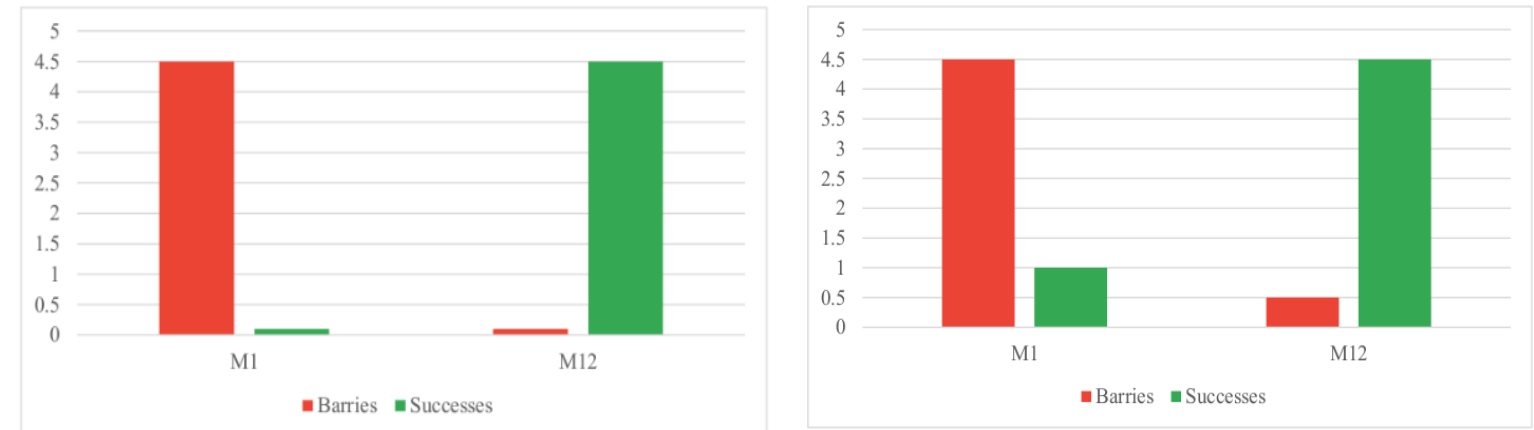

Figure 4 The Successes and the Barriers of participation of both boy (a) and girl (b) at the M1 and M12 with no support of special pedagogue

The SaSS training as pilot intervention showed that inclusive ER teams could be effective under identifying and specific roles and collaboration scripts that determine the steps of collaboration. The process of deepening concepts to participate effectively at the cognitive level remains to be further explored in mainstream research.

2nd Research question

Will the children with ASD increase the level of their autonomous implementation of the SaSS as suppliers in their teamwork? 
The level of autonomy differentiated between the two children and between SaSS steps. Figures 5 and 6 presents the Levels of the boy's and girl's with ASD autonomy in the implementation of the SaSS during the ER M1-M12

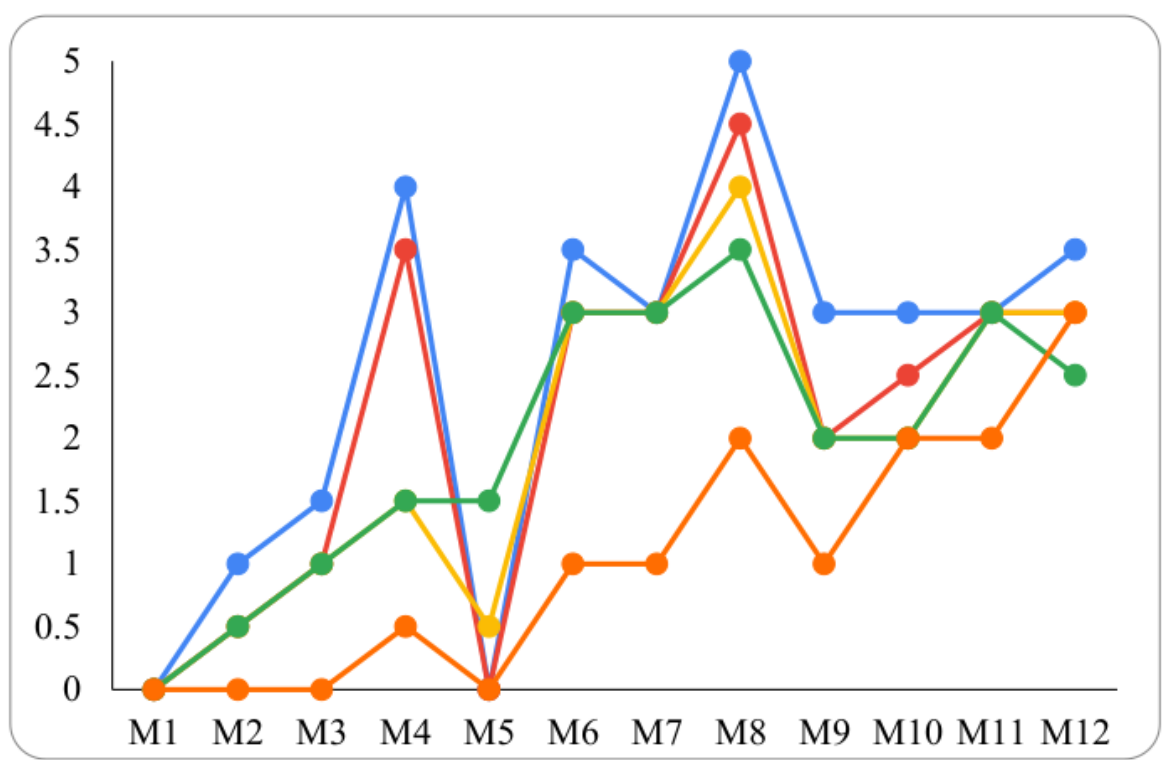

Figure 5 Levels of the boy's with ASD autonomy (0-5) in the implementation of the SaSS during the ER M1-M12

As presented in Figure 5, Christos at the first meeting of his team, rated 0 which means the absence of participation in teamwork. At M2-M3 at all the steps of SaSS declared an intention to participate in the teamwork by approaching the team or looking at the manual but his participation was unsure (rated 1 or 2). In the next, M4, he managed to follow the first two steps of the strategy (Come and Look) with his own effort and the other steps (Find and Give) with visual support and vertical prompts by the special pedagogue (rated 4). During M5 he needed support by physical guidance by the special pedagogue as he was disrupted, according to the observation diaries (rated 1 and 2). But in the next meetings (M6-M8) the physical guidance of the special educator was reduced. Christos could follow the steps of SaSS with virtual support. In the phase of programming (M8) he was able to independently conquer the first steps of the strategy (Come, Look, Look for) but he needed visual and verbal support to Find, Give steps of SaSS. Finally, during M9-M12 although the tasks for programming were more complex, the boy supplied the programming blocks in the canvas himself with only visual support. In the last two meetings, even if the task was more complicated, Christos followed SaSS steps with visual prompts and/or verbal guidance. 


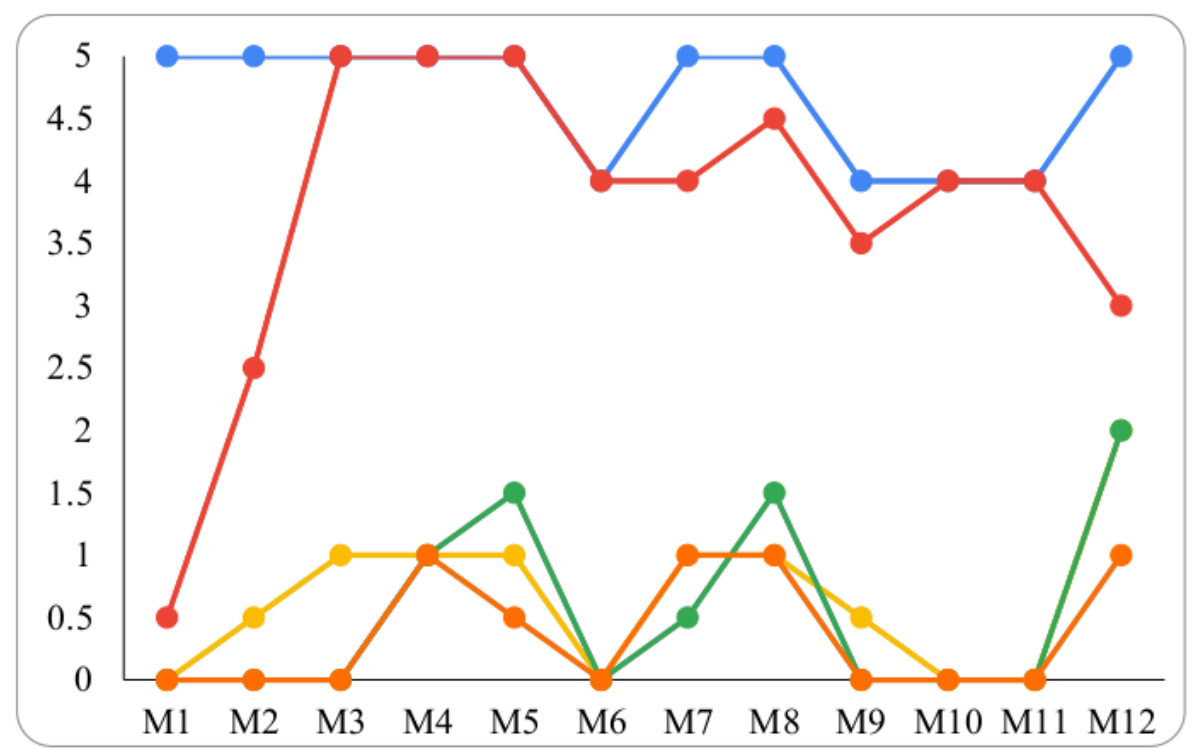

Figure 6 Levels of the girl's with ASD autonomy (0-5) in the implementation of the SaSS during the ER M1-M12

As presented in Figure 6, Lina's first meeting with the girls' team had positive results concerning the first two (2) SaSS steps. Lina rated 5 to the first two SaSS steps (Come, Look) as she independently approached and stayed close to the team without guidance. This was a stable characteristic of her participation in all the meetings. In contrast to Christos, she needed more support to apply the last steps of the strategy. More specifically during all the meetings graded 1 or 2 concerning the Look, Look for, Find and Give of SaSS steps, which means that she followed the SaSS to participate with physical guidance by the special pedagogue. This was the same also for the robot assembly meetings (M4-M5) and for the programming meetings. The need for guidance was ensured also by the observations of her participation according to which Lina was delayed and the special pedagogue with physical guidance helped her to be more effective. Only in the last meeting she completed the SaSS steps with the visual support and verbal guidance with the support of her team in the last two SaSS steps.

\section{Conclusions and Discussion}

The analysis of the findings leads to the following conclusions

Although the children with ASD with the need of substantial sup.port that were included in the two ER teams with typical peers during the educational intervention that was carried out, managed to "be on their roles" in teamwork as "suppliers" and to start functioning autonomously with the visual support of the SaSS. It is documented therefore, that SaSS Training fostered the participation of the two children with ASD in Level 2 in ER inclusive activities.

SaSS Training took place in authentic inclusive settings. It has to be mentioned that the children with ASD haven't got any special intervention before but were taught the SaSS in real time with their typical peers. By the observation of the children in the authentic learning environment drew to the conclusion the assignment of specific roles of the children in teamwork, the determination of the specific steps that the "supplier"could be followed as these steps were determined by the SaSS, the representation type and the support of special pedagogues created the circumstances of promoting the participation of both children with ASD in the construction and programming phases of the ER Lego Mindstorms activities. The support of special pedagogues progressively minimized. 
The educational Robots, Lego Mindstorms, functioned as "collaborative motivators". The choice of LEGO Mindstorms as the ER education kit was derived mainly because of their dominant acceptance and use in educational institutions. Also, LEGO Mindstorms has a widespread active community and supporting educational material. Learning practices through LEGO (only bricks) and LEGO Mindstorms (ER) especially for children with Autism Spectrum Disorders (ASD) are getting strong attention by education and academic society. LEGO, as structured, rule-based play, had strong evidence in facilitating social interaction and participation of children with ASD in team work with peers (Legoff, 2004; Legoff \& Sherman, 2006). The model structure for the assembling step by step as it was being represented in the detailed manual, proved an effective educational material suitable for children with ASD and challenging at the same time for typical children. The detailed visually structured manuals that are being described by (Lauwaert, 2008) proved very effective in inclusive settings where children with ASD are being included. LEGO Mindstorms NXT canvas was helpful for the children with autism to participate in the programming Phase. Their participation during the programming Phase fostered by using SaSS as Searching and Sharing the blocks in the programming canvas. SaSS in block programming has the meaning of Search and Sharing information ( programming blocks), while at constructing Phases has the meaning of Search and Share the real blocks. SaSS gave children the opportunity to participate actively and to be engaged in construction and in programming with peers just after 11 Meetings. The SaSS was used as a common communication code between the team members, and this gave them the confidence to continue their collaboration. According to the observations of the observatory "the children of typical development knew what to do to cooperate". The SaSS essentially contributed to leading and integrating the children into the teamwork so that the collaboration becomes more effective.

The educational intervention that was carried out continues the research on educational methods and strategies that can be applied in inclusive ER learning environments. Although the level of function of children that participated in this research was lower than the ones that had participated in inclusive ER in Australia (Hinchliffe et al., 2016), benefits documented by the research findings.

One of the main limitations of our educational intervention is the lack of control groups that could be left without intervention. In the inclusive settings it is not recemented, not an intervention without support to be applied. The absence of a control group is a usual methodological weakness in ER activities and especially in special or inclusive settings. According to the most recent review (Pivetti et al., 2020), eleven from thirteen research works in the field of ER programs addressed to people with disabilities didn't test their results in comparison with a control group. The lack of control group is expected due to the difficulties in the availability of participants. In these educational interventions the designing of research follows the restrictions of occasional participation.

As the field is new and the interest of researchers is really strong the research is under the circumstances of occasionality. Of course, the interpretation of the results has to take into consideration the specific limitations till the circumstances be more mature (e.g., ER be implemented in all populations in formal and non-formal education and their utilization will be spread in all educational settings). The other limitation is the small number of participants. In order for the results to be reliable the SaSS has to be taught to more children with ASD in inclusive settings.

Although the participation of the children with ASD was encouraging, future research has to focus on educational interventions that could foster the automatization of the SaSS in their teamwork as suppliers. Also, the investigation of functioning under differentiated roles (e.g., as builders) could be promising and helpful in promoting the participation of children with ASD in ER programmes. Also, future research has to investigate educational methodologies and 
strategies to increase the engagement of children with ASD in programming ER. The investigation of the subjective aspect of participation due to the Imms et al. (2017) model would be measured under the self assessment approach in order the engagement of persons with ASD to be globally estimated.

We do not know how the process of learning could go on if the research had the opportunity to deeply focus on programming. Children with autism at Level 2 may have the opportunity to understand fundamental computer programming concepts with the support of specific educational strategies as many researchers highlight for typical children (Afari \& Khine, 2017).

\section{References}

Afari, E., \& Khine, M. S. (2017). Robotics as an Educational Tool: Impact of Lego Mindstorms. International Journal of Information and Education Technology, 7(6), 437-442. https://doi.org/10.18178/ijiet.2017.7.6.908

Albo-Canals, J., Fernández-Baena, A., Boldu, R., Barco, A., Navarro, J., Miralles, D., Raya, C., \& Angulo, C. (2015). Enhancing Long-term Children to Robot Interaction Engagement through Cloud Connectivity. Proceedings of the Tenth Annual ACM/IEEE International Conference on Human-Robot Interaction Extended Abstracts, 105-106. https://doi.org/10.1145/2701973.2702045

American Psychiatric Association. (2013). Diagnostic and statistical manual of mental disorders (DSM-5). American Psychiatric Association Publishing. https://doi.org/10.1176/appi.books.9780890425596

Askari S., Anaby D., \& Bergthorson M. (2015). Participation of children and youth with autism spectrum disorder: a scoping review. Rev J Autism Dev Disord, 2(1), 103-114.

Barker, B.S. \& Ansorge, J. (2007). Robotics as means to increase achievement scores in an informal learning environment.Journal of Research on Technology in Education, 39(3), $229-43$.

Bell, P. (2004). Promoting students' argument construction and collaborative debate in the science classroom. In M. Linn, E. A. Davis \& P. Bell (Eds.), Internet environments for science education (pp. 115-143). Mahwah (NJ): Lawrence Erlbaum Associates.

Benitti, F. B. V. (2012). Exploring the educational potential of robotics in schools: A systematic review. Computers \& Education, 58(3), 978-988. https://doi.org/10.1016/j.compedu.2011.10.006

Bernstein, D., Karen Mutch-Jones K., Michael Cassidy, M., \& Emily Hamner, E, (2020): Teaching with robotics: creating and implementing integrated units in middle school subjects, Journal of Research on Technology in Education. https://doi.org/10.1080/15391523.2020.1816864

Blanchard, S., Freiman, V., \& Lirrete-Pitre, N. (2010). Strategies used by elementary school children solving robotics-based complex tasks: Innovative potential of technology. Procedia - Social and Behavioral Sciences, 2(2), 2851-2857.

https://doi.org/10.1016/j.sbspro.2010.03.427

Carpenter, B., Carpenter, J., Egerton, J., \& Cockbill, B. (2016). The Engagement for Learning Framework: Connecting with learning and evidencing progress for children with autism spectrum conditions. Advances in Autism, 2, 12-23. https://doi.org/10.1108/AIA-102015-0021

John W., Creswell, W. E., Hanson, V.L., Clark P., \& Alejandro M. (2007). Qualitative Research Designs: Selection and Implementation-(n.d.). Retrieved October 30, 2021, from https://journals.sagepub.com/doi/10.1177/0011000006287390 
Damaskinidis, G. \& Christodoulou, A. (2019). Writing Research Proposals for the Social Sciences and Humanities in a Higher Education Context. Cambridge, Scholars Publishing, UK.

Daniela, L. \& Lytras, M.D., (2019). Educational Robotics for Inclusive Education. Tech Know Learn 24, 219-225. https://doi.org/10.1007/s10758-018-9397-5

Dillenbourg, P. (2002). Over-scripting CSCL: The risks of blending collaborative learning with instructional design. In P. A. Kirschner (Ed.), Three worlds of CSCL. Can we support CSCL (pp. 61-91). Heerlen: Open Universiteit Nederland.

Feldman,A., Altrichter,H., Posch,P., \& Somekh, B. (2018). Teachers Investigate Their Work, An Introduction to Action Research across the Professions. Routledge.

Hampshire, P. K. \& Hourcade, J. J. (2014). Teaching Play Skills to Children with Autism Using Visually Structured Tasks. TEACHING Exceptional Children, 46(3), 26-31. https://doi.org/10.1177/004005991404600303

Hewitt, J. (2005). Toward an understanding of how threads die in asynchronous computer conferences. Journal of the Learning Sciences, 14(4), 567-589.

Hinchliffe, K., Saggers, B., Chalmers, Ch., \& Hobbs, J. (2016). Utilising robotics social clubs to support the needs of students on the autism spectrum within inclusive school settings. Autism CRC - Cooperative Research Centre for Living with Autism, Australia.

Hutchinson, L. (1999). Evaluating and researching the effectiveness of educational interventions. BMJ (Clinical research ed.), 318(7193), 1267-1269. https://doi.org/10.1136/bmj.318.7193.1267

Imms, C., Granlund, M., Wilson, P.H., Steenbergen, B., Rosenbaum, P.L., \& Gordon, A.M. (2017). Participation, both a means and an end: a conceptual analysis of processes and outcomes in childhood disability. Dev Med Child Neurol, 59: 16-25. https://doi.org/10.1111/dmcn.13237

Iovannone, R., Dunlap, G., Huber, H., \& Kincaid, D. (2003). Effective educational practices for students with autism spectrum disorders. Focus on Autism and Other Developmental Disabilities, 18(3), 150-65.

Isari, F. \& Purkos, M. (2015). Qualitative research methodology. Applications in psychology and education. Retrieved from https://repository.kallipos.gr/bitstream/11419/5826/4/15327_Isari-KOY.pdf

Kollar, I., Fischer, F., \& Hesse, F. W. (2006). Collaboration Scripts - A Conceptual Analysis. Educational Psychology Review, 18(2), 159-185. https://doi.org/10.1007/s10648-006$\underline{9007-2}$

Lauwaert, M. (2008). Playing outside the box - on LEGO toys and the changing world of construction play. History and Technology, 24(3), 221-237. https://doi.org/10.1080/07341510801900300

Legoff, D. B., \& Sherman, M. (2006). Long-term outcome of social skills intervention based on interactive LEGOplay. Autism, 10(4), 317-329. https://doi.org/10.1177/1362361306064403

Legoff, D. B. (2004). Use of LEGO as a Therapeutic Medium for Improving Social Competence. Journal of Autism and Developmental Disorders, 34(5), 557-571. https://doi.org/10.1007/s10803-004-2550-0

Liu, C. \& Tsai, C. (2008). An analysis of peer interaction patterns as discoursed by on-line small group problem - solving activity. Computers and Education, 50(3), 627-639.

Mesibov, G. B. \& Howley, M. (2003). Accessing the curriculum for pupils with autistic spectrum disorders. Using the TEACCH programme to help inclusion. London: David Fulton Publishers. 
Miller, D. P., Nourbakhsh, I. R., \& Siegwart, R. (2008). Robots for Education. In B. Siciliano \& O. Khatib (Eds.), Springer Handbook of Robotics (pp. 1283-1301). Berlin Heidelberg: Springer Berlin Heidelberg. https://doi.org/10.1007/978-3-540-30301-5_56

Nanou, A., Giatrakou,A., \& Maistrellis A.(2020). Learning how to fall, to standup and demand. Grafima Publications Thessaloniki.

Nilholm, C. (2021). How can we improve our theories in order to change practice? European Journal of Special Needs Education, 36(3), 358-370. https://doi.org/10.1080/08856257.2020.1754547

Pang, Y. (2010). Lego Games Help Young Children with Autism Develop Social Skills. International Journal of Education, 2(2), E7. https://doi.org/10.5296/ije.v2i2.538

Pivetti, M., Di Battista, S., Agatolio, F., Simaku, B., Moro, M., \& Menegatti, E. (2020). Educational Robotics for children with neurodevelopmental disorders: A systematic review. Heliyon, 6(10), e05160. https://doi.org/10.1016/j.heliyon.2020.e05160

Sanneman, L., Fourie, C., \& Shah, J. (2020). The State of Industrial Robotics: Emerging Technologies, Challenges, and Key Research Directions. Retrieved from https://arxiv.org/abs/2010.14537

Seale, J., Nind M., \& ParsonsS. (2014). Inclusive research in education: contributions to method and debate.International Journal of Research \& Method in Education, 37(4), 347-356. https://doi.org/10.1080/1743727X.2014.935272

Stevens, D. \& Levi, A. (2005). Leveling the field : Using rubrics to achieve greater equity in teaching and grading. The professional and organizational development network in higher education, 17(1). Retrieved from https://pdxscholar.library.pdx.edu/cgi/viewcontent.cgi?article=1087\&context=edu_fac

Silva, L., Mendes, A. J., \& Gomes, A. (2020). Computer-supported Collaborative Learning in Programming Education: A Systematic Literature Review. 2020 IEEE Global Engineering Education Conference (EDUCON) Proceedings, 1086-1095. https://doi.org/10.1109/EDUCON45650.2020.9125237

Simpson, K., Imms, C., \& Keen, D. (2021). The experience of participation: eliciting the views of children on the autism spectrum. Disability and Rehabilitation. https://doi.org/10.1080/09638288.2021.1903100

Tsiomi, E. \& Nanou, A. (2020). Cooperative strategies for children with Autism Spectrum Disorders Autism spectrum disorders in inclusive robotics activities". Society. Integration. Education, 5, 148-156. https://doi.org/10.17770/sie2020vol4.5147

Tsiomi, E., Paschalidou, A., \& Nanou, A. (2020). Social story intervention for a child with autism in out of school robotic activities. 3rdInternational Experiential Conference on Applied Teaching New Challenges in Education.Greece, 2- 4 October.

Yuen, T. T., Mason, L. L., \& Gomez, A. (2014). Collaborative Robotics Projects for Adolescents with Autism Spectrum Disorders. Journal of Special Education Technology, 29(1), 51-62. https://doi.org/10.1177/016264341402900104

Vygotsky, L. S. (1978). Mind and society: The development of higher mental processes. Harvard, University Press, Cambridge, MA:. Harvard, University Press.

Vygotsky, L. S. (1992). Thought and language (rev. ed.). The MIT Press, Cambridge, MA.

Wainer, J., Ferrari, E., Dautenhahn, K., \& Robins, B. (2010). The effectiveness of using a robotics class to foster collaboration among groups of children with autism in an exploratory study. Personal and Ubiquitous Computing, 14(5), 445-455. https://doi:10.1007/s00779-009-0266-Z

Warren, Z. E., Zheng, Z., Swanson, A. R., Bekele, E., Zhang, L., Crittendon, J. A., Weitlauf, A. F., \& Sarkar, N. (2015). Can Robotic Interaction Improve Joint Attention Skills? Journal Of Autism and Developmental Disorders, 45(11), 3726-3734. https://doi.org/10.1007/s10803-013-1918-4 
Willig, C. (2008). Introducing Qualitative Research in Psychology: Adventures in Theory and Method. 2nd ed. Maidenhead: Open University Press.

Wood, D., Bruner, J., \& Ross, G. (1976). The role of tutoring in problem solving. Journal of Child Psychology and Child Psychiatry, 7 https://doi.org/10.1111/j.14697610.1976.tb00381.x 